\title{
ÓleO ESSENCIAL DE PITANGUEIRA NA GERMINAÇÃo E SANIDADE DE SEMENTES DE VARIEDADES CRIOULAS DE FEIJOEIRO
}

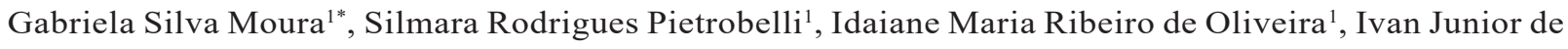
Oliveira $^{1}$, Gilmar Franzener ${ }^{1}$

\begin{abstract}
RESUMO - Diversos fitopatógenos podem afetar a sanidade de sementes de feijoeiro. Esse trabalho objetivou avaliar o efeito do óleo essencial (OE) de pitanga na incidência de patógenos e germinação de sementes de feijoeiro. O delineamento experimental foi inteiramente casualizado com cinco tratamentos e quatro repetições. O OE de pitangueira foi avaliado nas concentrações de $0 ; 0,05 \% ; 0,1 \% ; 1 \%$ e $2 \%$. As sementes foram imersas nos tratamentos por cinco minutos e acondicionadas em gerbox contendo papel de germinação. Foram avaliadas a porcentagem de germinação, plântula normal e anormal, comprimento de parte área e de raiz e massa da matéria fresca e seca. Também foi realizado teste de patologia de sementes com avaliação da incidência de fungos e bactérias. Foram utilizadas as variedades Mourinho e Rajado Vermelho.. Foram identificados nas duas variedades os patógenos dos gêneros Fusarium, Penicillium, Aspergillus, Colletotrichum, Bacillus e Xanthomonas. $\mathrm{O}$ OE de pitanga promoveu redução na incidência do fungo Fusarium na variedade Rajado Vermelho. Embora tenha apresentado efeito protetor, o óleo essencial, nas maiores concentrações, também apresentou efeito inibitório sobre o desenvolvimento de plântulas normais e sobre atributos do desenvolvimento das plântulas, indicando efeito fitotóxico nas maiores concentrações.
\end{abstract}

Palavras-chave: Eugenia uniflora, patologia de sementes, Phaseolus vulgaris.

\section{ESSENTIAL OIL OF SURINAM CHERRY IN THE GERMINATION AND SANITY OF BEAN LANDRACE VARIETIES}

\begin{abstract}
Several phytopathogens can affect the health of common bean seeds. The aim of this work was evaluate the effect of essential oil (EO) of Surinam Cherry on the pathogen incidence and seed germination of common bean. The experimental design was completely randomized with four replicates. The Surinam Cherry EO was evaluated at concentrations of $0 ; 0.05 ; 0.1 ; 1$ and 2\%. The seeds were immersed in the treatments for five minutes and packed in a gerbox containing germination paper. The percentage of germination, normal and abnormal seedling, area and root length and fresh and dry matter mass were evaluated. A seed pathology test was also carried out, evaluating the incidence of fungi and bacteria. The Mourinho and Rajado Vermelho varieties were used. Pathogens of the genus Fusarium, Penicillium, Aspergillus, Colletotrichum, Bacillus and Xanthomonas were identified in both varieties. The OE promoted a reduction in the incidence of Fusarium fungus in the Rajado Vermelho variety. Although it had a protective effect, the essential oil, at the highest concentrations, also had an inhibitory effect on the development of normal seedlings and on attributes of seedling development, indicating a phytotoxic effect at the highest concentrations.
\end{abstract}

Keywords: Eugenia uniflora, Phaseolus vulgaris, seed pathology.

\footnotetext{
${ }^{1}$ Universidade Federal da Fronteira Sul - UFFS, Campus Laranjeiras do Sul-PR, BR 158, km 405, CEP 85301-970. *Autor para correspondência: bismoura@hotmail.com
} 


\section{INTRODUÇÃO}

O feijoeiro comum (Phaseolus vulgaris L.) é um das leguminosas mais importantes do mundo, sendo de grande relevância econômico-social (Stone et al., 2013).

O Brasil foi considerado o maior produtor mundial de feijão, na safra de $2015 \backslash 2016$ a produção nacional de grãos foi 2.593,1 toneladas, e estima-se que para $2016 \backslash 2017$ chegue a 3.052,3 milhões de toneladas, segundo dados da Conab (2017).

A cultura do feijoeiro pode ser afetada por diversas doenças que afetam a produtividade. Grande parte dos agentes etiológicos das doenças do feijoeiro pode ser transportada pela semente (Wendland et al., 2016), contribuindo para ocorrência de epidemias nas lavouras (Souza, 2016).

A importância dos testes de detecção de fungos patogênicos em sementes, deve-se ao fato que as mesmas funcionam como meio de sobrevivência do patógeno, além de serem veículos de disseminação para outras áreas não infestadas (Rey et al., 2009). Os danos decorrentes da associação patógenos com semente resultam na redução da qualidade das sementes, dispersão de raças mais agressivas e transmissão do patógeno já nos primeiros estágios de desenvolvimento da planta (Rani et al., 2013).

Neste contexto, é importante salientar que um dos aspectos essenciais relacionados à produtividade de uma cultura é a utilização de sementes de alta qualidade sanitária. Partir de aspectos que envolvem a qualidade sanitária das sementes é essencial, pois grande número de microrganismos pode estar associado a elas, causando anormalidades nas plântulas, deterioração do tecido embrionário, afetando a germinação e vigor e consequentemente a produção (Piveta et al., 2010).

Segundo Zuchi et al. (2013), a qualidade das sementes compreende um conjunto de atributos que envolve o genótipo, condições edáficas, climáticas e fatores bióticos, além de condições adequadas de temperatura e umidade (Figueiredo Neto et al., 2012). A qualidade fisiológica das sementes é definida como a capacidade de desempenhar suas funções vitais, caracterizadas pela longevidade, viabilidade e vigor (Toledo et al., 2009). O tratamento de sementes constitui uma medida importante no manejo integrado de doenças de plantas (Menten, 1995). Para o tratamento de sementes comumente são utilizados fungicidas, mas ainda há poucas informações de alternativas ao uso de produtos químicos. Entre essas alternativas o uso de óleos essenciais de plantas já tem demonstrado potencial (Bozic et al., 2017; Girardi et al., 2017).

Em pesquisas envolvendo a sanidade e germinação de sementes de feijão-fava, foi avaliada a eficiência de óleos essenciais na incidência de fungos e qualidade fisiológica das sementes (Gomes et al., 2016), onde os autores verificaram que os óleos essenciais de copaíba e manjericão reduziram a incidência de fungos nas sementes.

Segundo Lopes et al. (2000), sementes de feijãomacassar tratadas com os produtos naturais à base de raspas de fumo em rolo, pó de casca dos frutos de laranja cravo e de frutos de pimenta-do-reino moídos, apresentaram baixo nível de infestação por insetos durante o armazenamento, sendo uma alternativa em substituição ao tratamento químico das sementes.

Conforme mencionam Barrocas \& Machado (2010), a utilização de produtos naturais como o uso de óleos essenciais no controle de patógenos presentes nas sementes, pode reduzir o uso de produtos químicos, além de diminuir os riscos à saúde humana e ao ambiente. No entanto, ainda são poucos estudos realizados com sementes crioulas, também conhecidas como locais ou tradicionais. Alguns óleos essenciais, como o de pitangueira (Eugenia uniflora L.), tem conhecidas atividades antimicrobianas e antioxidantes (Victoria et al., 2012), mas são escassas as informações do potencial para o tratamento de sementes. Diante do exposto, o objetivo desse trabalho foi avaliar o efeito de diferentes concentrações do óleo essencial de pitangueira na germinação e na incidência de patógenos em sementes de feijão var. Mourinho e var. Rajado Vermelho.

\section{MATERIAL E MÉTODOS}

O experimento foi conduzido no laboratório de Fitopatologia da Universidade Federal da Fronteira Sul no Campus Laranjeiras do Sul-PR, em agosto de 2016. As coordenadas geográficas da região são $25^{\circ} 26^{\prime} 42$ ' de latitude Sul e 52²6'29' longitude Oeste. Foram utilizadas duas variedades de sementes de feijão var. Mourinho e var. Rajado Vermelho, adquiridas de agricultores do município de Laranjeiras do Sul-PR. Para o teste de patologia, as sementes de feijoeiro de 
cada variedade foram inicialmente desinfectadas em solução de hipoclorito de sódio $0,5 \%$ por um min, e em seguida lavadas em água destilada. As sementes foram imersas por cinco minutos nos seguintes tratamentos: óleo essencial de pitanga (OE) na concentração de $0 ; 0,05 \% ; 0,1 \% ; 1 \%$ e $2 \%$. Para todos os tratamentos utilizou-se $0,5 \%$ de Tween 20 . Após as sementes foram secas em papel absorvente, foram distribuídas em caixas tipo gerbox contendo duas folhas de papel de germinação previamente umedecido com água destilada equivalente a 2,5 vezes o peso seco. Foram dispostas 25 sementes por gerbox em quatro repetições, totalizando 100 sementes por tratamento, em seguida incubadas em germinador do tipo $\mathrm{BOD}$ a $25^{\circ} \mathrm{C} \pm 2^{\circ} \mathrm{C}$, no escuro. Após 24 horas de incubação as sementes foram transferidas para congelador a $-20^{\circ} \mathrm{C}$, sendo mantidas por 12 horas. Após esse período foram novamente incubadas em BOD. Sete dias após, foi realizada a avaliação da incidência de fungos e bactérias nas sementes pela contagem de sementes infectadas e auxílio de chaves de identificação (Barnett \& Hunter, 1982).

No teste de germinação, foram adotados os mesmos procedimentos citados anteriormente para o teste de patologia, mas nesse caso as sementes foram mantidas somente em BOD, sem congelamento. Aos nove dias após a implantação do experimento avaliou-se as seguintes variáveis: porcentagem de germinação, plântulas normais e anormais, comprimento da parte área e da raiz e peso total da matéria fresca. Após $24 \mathrm{~h}$ avaliou-se o peso total da matéria seca das amostras submetidas a $70^{\circ} \mathrm{C}$ (Brasil, 2009).

Os bioensaios foram conduzidos em delineamento experimental inteiramente casualizado com quatro repetições sendo cada repetição constituída por vinte e cinco sementes, totalizando 100 sementes por tratamento. Para análise estatística os resultados foram submetidos inicialmente a testes de normalidade e homogeneidade, sendo transformados para análise quando necessário. Os resultados foram submetidos à análise de variância e estudo da regressão para as concentrações do óleo essencial de pitanga. Análises foram realizadas com auxílio do programa computacional Sisvar 5.6. (Ferreira, 2011).

\section{RESULTADOS E DISCUSSÃO}

No teste de patologia de sementes foram identificados, em ambas as variedades de sementes de feijoeiro, var. Mourinho e var. Rajado Vermelho, os fitopatógenos dos gêneros Fusarium, Penicillium, Aspergillus, Colletotrichum, Bacillus e Xanthomonas (Figura 1).

O gênero Fusarium apresentou maior incidência, e para o qual o óleo essencial de pitangueira promoveu redução linear, principalmente na variedade Rajado Vermelho com inibição de 48,2\% na incidência do fungo na concentração de $2 \%$. (Figura 1). Para os demais gêneros encontrados não houve diferença significativa. De maneira geral, maiores valores de incidência de potenciais fitopatógenos foi observada na var. Rajado Vermelho.

Os fitopatógenos que ocorreram nesse trabalho são comuns em feijoeiro e podem causar sérios danos
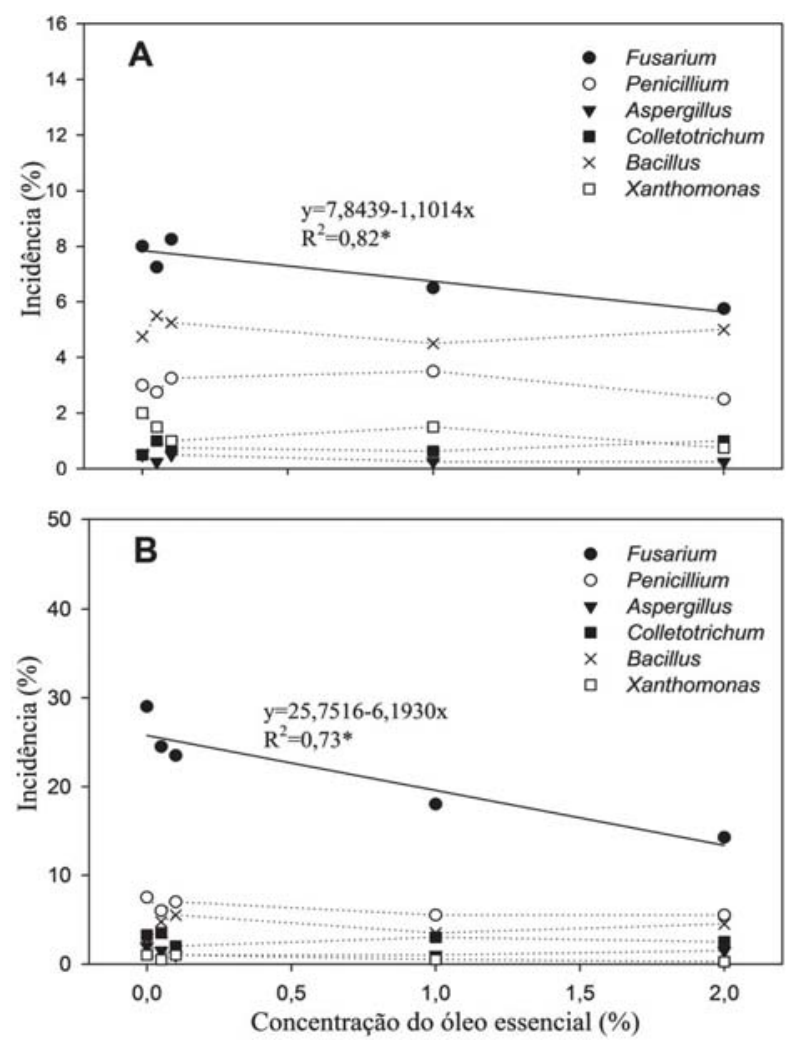

Figura 1 - Incidência de fungos e bactérias em sementes de feijoeiro var. Mourinho (A) e var. Rajado Vermelho (B) submetidas ao tratamento com diferentes concentrações do óleo essencial de pitangueira. *Significativo a $5 \%$ de probabilidade. 
às sementes da cultura. $\mathrm{O}$ fato de o óleo essencial de pitanga reduzir significativamente a incidência do fungo Fusarium, o de maior ocorrência em ambas as variedades, indica o potencial do óleo essencial dessa espécie. Embora derivados vegetais tenham sido mais estudados no controle de doenças de parte aérea (Costa et al., 2017), alguns trabalhos já relataram o potencial de outros óleos essenciais na sanidade de sementes (Gomes et al., 2016). O tratamento de sementes com óleos essenciais pode representar importante alternativa em sistemas de base ecológica, pois podem ser utilizados mesmo em baixas concentrações, o que também pode viabilizar o uso em maior escala. O desenvolvimento de novas tecnologias no tratamento de sementes torna-se fundamental para ganhos na produção das culturas (Aguilera \& Martín, 2016). Entre os trabalhos recentes que demonstraram o potencial de óleos essenciais no tratamento de sementes, Girardi et al. (2017), avaliaram o efeito da microencapsulação com óleo essencial de Lipia turbinata em sementes de amendoim e verificaram eficiência na redução de fungos nas sementes, principalmente dos gêneros Penicillium e Aspergillus. No trabalho desenvolvido por Bozik et al. (2017), além de ser verificado efeito antifúngico sobre Aspergillus spp. em sementes de aveia por diversos óleos essenciais, também verificaram que houve alteração na característica sensorial das sementes, com exceção para óleo essencial de capim-limão. No entanto, a característica sensorial é de menor importância para o caso de tratamento de sementes que não serão destinadas diretamente para o consumo. Efeito do óleo essencial de outras espécies também tem sido observado sobre fungos do gênero Fusarium spp. (Hashem et al., 2010), de acordo com os resultados obtidos nesse trabalho.

Sobre a germinação das sementes de feijoeiro não foi observada diferença significativa pela utilização do óleo essencial, mesmo em maiores concentrações (Figura 2). Tal comportamento foi observado para ambas as variedades.

Por outro lado, o óleo essencial de pitangueira promoveu diminuição na porcentagem de plântulas normais (Figura 3A) e aumento no desenvolvimento de plântulas anormais (Figura 3B). Foi observado efeito semelhante para ambas às variedades.

A ausência de efeito tóxico do óleo essencial de pitanga na germinação de sementes de feijoeiro é desejada, no entanto foi observado que em maiores

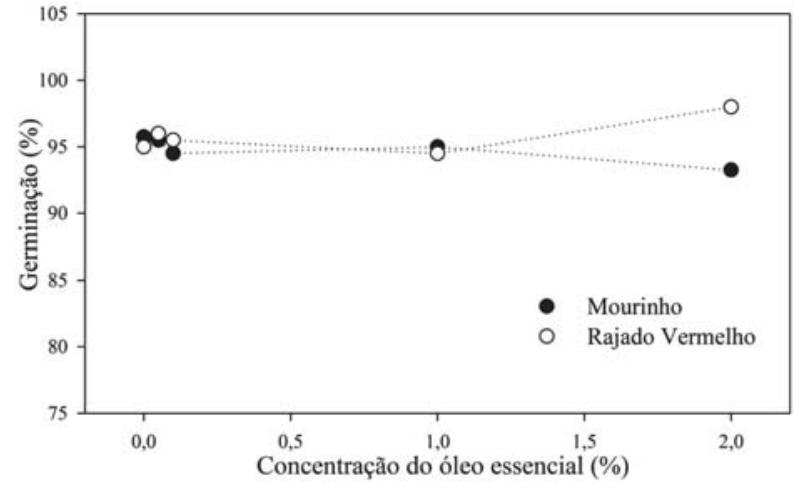

Figura 2 - Porcentagem de germinação sementes de feijoeiro após tratamento das sementes com diferentes concentrações do óleo essencial de pitangueira.
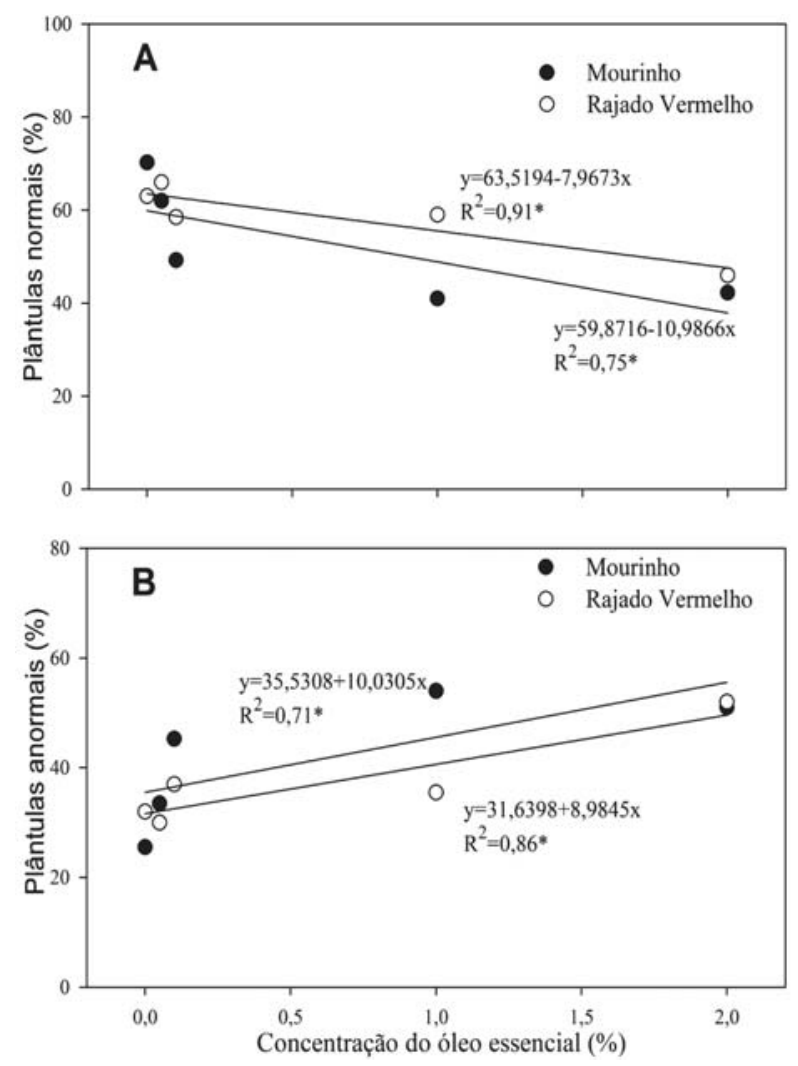

Figura 3 - Porcentagem de plântulas normais (A) e anormais (B) de plântulas de feijoeiro após tratamento das sementes com diferentes concentrações do óleo essencial de pitangueira. *Significativo a $5 \%$ de probabilidade. 
concentrações o óleo essencial pode afetar atributos relacionados ao desenvolvimento das plântulas, indicando efeito fitotóxico em maiores concentrações. Os óleos essenciais tendem a possuir composição complexa (Mesquita et al., 2017) e concentrada, o que contribui para justificar seu efeito mesmo em baixas concentrações e efeitos tóxicos em altas concentrações.

Para o comprimento da parte aérea houve comportamento distinto entre as variedades, sendo que o óleo essencial promoveu inibição apenas sobre a variedade Mourinho, que foi de 38,6\% em relação ao tratamento sem óleo essencial (Figura 4A). Quanto ao desenvolvimento da radícula também apenas houve efeito sobre a var. Mourinho, nesse caso com efeito quadrático e ponto de máximo comprimento da radícula promovido na concentração de $0,99 \%$ do óleo essencial (Figura 4B).
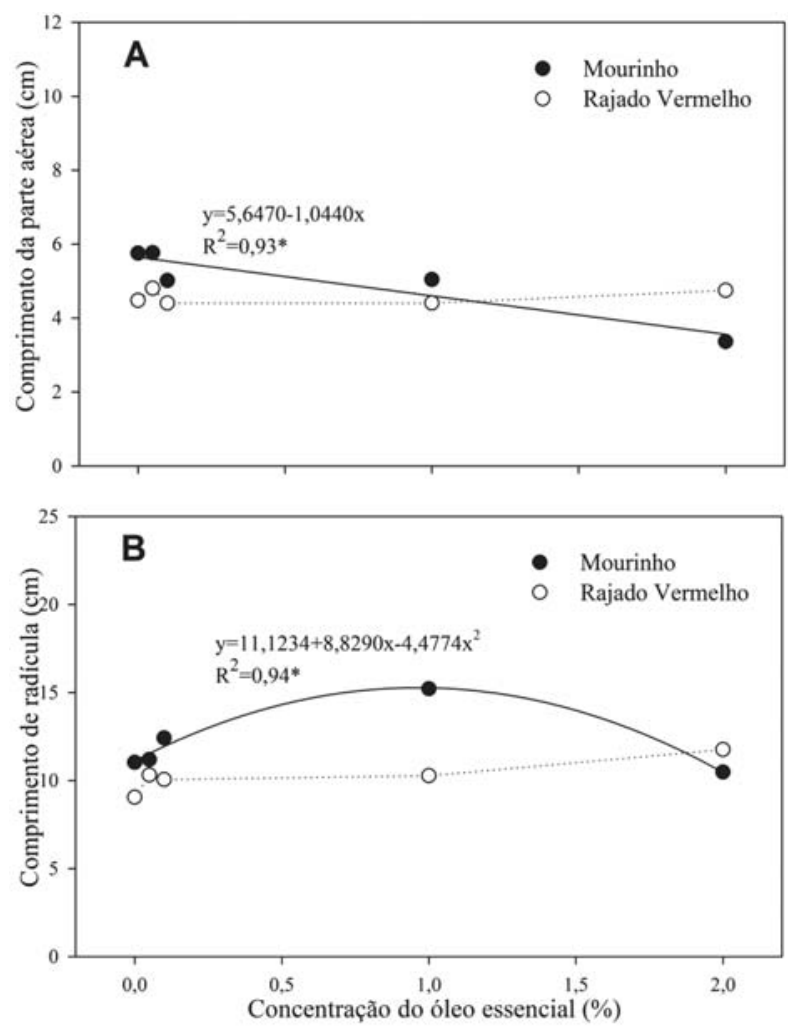

Figura 4 - Comprimento da parte aérea (A) e da radícula (B) de plântulas de feijoeiro após tratamento das sementes com diferentes concentrações do óleo essencial de pitangueira. *Significativo a $5 \%$ de probabilidade.
Para massa da matéria fresca houve redução linear para var. Mourinho, sendo de 52,8\% na concentração de $2 \%$ do óleo essencial. Para variedade Rajado Vermelho não foi observada diferença significativa. Também não foi observada diferença para massa da matéria seca, independentemente da variedade utilizada (Figura 5).

Os resultados obtidos nesse trabalho são reforçados por Gomes et al. (2016) que ressaltam que os óleos essenciais, quando utilizados puros, podem apresentar toxicidade elevada nos vegetais. Em função disso, recomenda-se a utilização de pequenas dosagens onde desenvolvem funções que estão relacionadas à sua volatilidade (Bozik et al., 2017), agindo na proteção de plantas. No entanto, a presença de efeito fitotóxico dependerá das espécies vegetais estudadas. Lobato et al. (2007) mostraram que a ação do óleo essencial
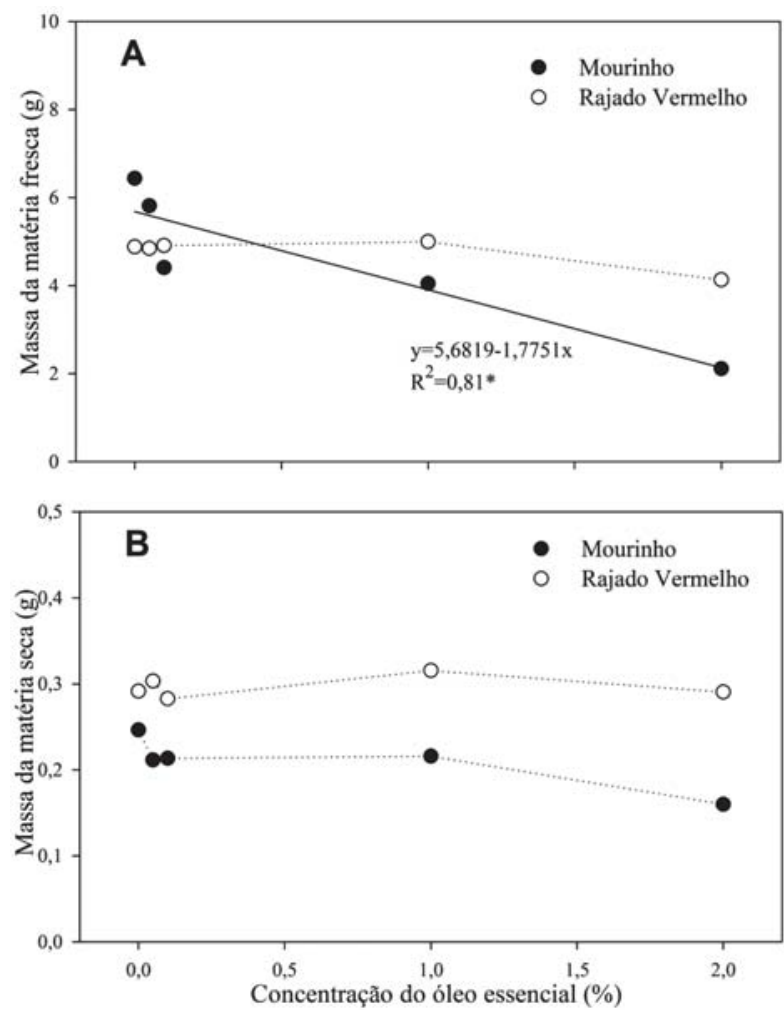

Figura 5 - Massa de matéria fresca (A) e seca (B) de plântulas de feijoeiro após tratamento das sementes com diferentes concentrações do óleo essencial de pitangueira. *Significativo a $5 \%$ de probabilidade. 
de Pipper aducum no tratamento de sementes de feijão Vigna unguiculata não apresentou respostas fitotóxicas sobre a germinação, mesmo em altas concentrações do óleo.

Outro aspecto importante observado foi o efeito diferencial entre as duas variedades de feijoeiro avaliadas para aspectos do desenvolvimento de plântulas. Embora houveram resultados semelhantes para incidência de fitopatógenos, germinação e porcentagem de plântulas normais, a variedade Mourinho se mostrou mais sensível ao efeito do óleo essencial de pitangueira para comprimento de radícula, da parte aérea e matéria fresca. Assim, essas respostas diferenciais entre as variedades ao tratamento com óleo essencial é um aspecto importante a ser considerado em pesquisas ou mesmo na recomendação prática do tratamento de sementes com óleos essenciais, de maneira que possam ser utilizadas concentrações eficientes, mas que não venham a comprometer negativamente o desenvolvimento de determinadas variedades.

Delgado \& Barbedo (2011), avaliaram o potencial inibidor de extratos de sementes germinantes de pitangueira sobre a germinação de suas próprias sementes e de sementes de feijão e aquênios de alface. Esses autores verificaram que os extratos de pitangueira não apresentaram inibição da germinação para a própria espécie. Porém, para os aquênios de alface e sementes de feijão houve inibição da germinação e do desenvolvimento inicial das plântulas.

Singh et al. (1991) avaliaram o efeito direto de compostos voláteis liberados pelas folhas de eucalipto (Eucalyptus globulus e Corymbia citriodora) no crescimento de feijoeiro. Os autores verificaram que, os vapores do óleo essencial de eucalipto, quando adsorvidos nas partículas do solo, retêm sua atividade e inibem a germinação de sementes e crescimento de mudas de feijoeiro. Ainda ressaltam que, o efeito inibitório dos óleos de folhas de eucalipto ou dos seus componentes ricos (cineol e limoneno) é aumentado se o ar acima do substrato tiver também os vapores destes óleos adsorvidos ou suspensos.

Os resultados obtidos nesse trabalho com óleo essencial de E. uniflora demonstram o potencial uso do mesmo mas também reforçam a necessidade de aprofundar os estudos para compreensão de concentrações e formas mais adequadas de utilização para viabilizar o emprego.

\section{CONCLUSÕES}

O óleo essencial de pitanga promoveu redução na incidência do fungo Fusarium na variedade Rajado Vermelho.

O óleo essencial de pitanga, nas maiores concentrações, apresentou efeito inibitório no desenvolvimento das plântulas de feijoeiro, indicando efeito fitotóxico nas maiores concentrações.

\section{AGRADECIMENTO}

Os autores agradecem à Coordenação de Aperfeiçoamento de Pessoal de Nível Superior (CAPES) pela concessão de bolsa PNPD.

\section{LITERATURA CITADA}

AGUILERA, J.G.; MARTÍN, R.M. Água tratada magneticamente estimula a germinação e desenvolvimento de mudas de Solanum lycopersicum L. Revista Brasileira de Agropecuária Sustentável, v.6, n.1, p.47-53, 2016.

BARNETT; H.L.; HUNTER, B.B. Illustrated genera of imperfect fungi. 3.ed. Minessota: Burgess, 1982. 242p.

BARROCAS, E.N.; MACHADO. J.C. Inovações tecnológicas em patologia de sementes. Introdução a patologia de sementes e testes convencionais de sanidade de sementes para a detecção de fungos fitopatogênicos.

Informativo ABRATES, v.20, n.3. p.10-13, 2010

BOZIK, M.; CÍSAROVÁ, M.; TANCINOVÁ, D. et al. Selected essential oil vapours inhibit growth of Aspergillus spp. in oat with improved consumer acceptability. Industrial Crops and Products, v.98, p.146-152, 2017.

BRASIL. Ministério da Agricultura, Pecuária e Abastecimento. Regras para análise de sementes / Ministério da Agricultura, Pecuária e Abastecimento. Secretaria de Defesa Agropecuária. - Brasília: Mapa/ACS, 2009. 399p. 
CONAB - Companhia Nacional de Abastecimento. Observatório Agrícola. Acompanhamento da safra brasileira grãos. Safra 2016/2017, v.4, n.1, Brasília, 2017.

COSTA, R.C.; ISHIDA, A.K.N.; MIRANDA, V.S. et al. Extratos vegetais, formulações a base de extrato vegetal e produtos químicos no controle da mancha bacteriana do maracujazeiro. Revista Brasileira de Agropecuária

Sustentável, v.7, n.1, p.23-33, 2017.

DELGADO, L.F.; BARBEDO, C.J. Atividade inibidora da germinação em extratos de sementes Eugenia uniflora L. Revista Brasileira de Sementes, v.33, n.3, p.463-471, 2011.

FERREIRA, D.F. Sisvar: A computer statistical analysis system. Ciência e Agrotecnologia, v.35, n.6, p.1039-1042, 2011.

FIGUEIREDO NETO, A.; LIMA, M.S.; SILVA, M.F. et al. Armazenamento e qualidade fisiológica de sementes de abóbora. Revista Brasileira de Agropecuária Sustentável, v.2, n.2, p.44-50, 2012.

GIRARDI, N.S.; GARCÍA, D.; PASSONE, M.A. et al. Microencapsulation of Lippia turbinata essential oil and its impact on peanut seed quality preservation. International

Biodeterioration \& Biodegradation, v.116, p.227-233, 2017.

GOMES, R.S.S.; NUNES, M.C.; NASCIMENTO, L.C. et al. Efficiency of essential oils in the sanitary and physiological quality of lima bean seeds (Phaseolus lunatus L.). Revista Brasileira de Plantas Medicinais, v.18, n.1, p.279-287, 2016.

HASHEM, M.; MOHARAM, A.M.; ZAIED, A.A. et al. Efficacy of essential oils in the control of cumin root rot disease caused by Fusarium spp. Crop Protection, v.29, p.1111-1117, 2010.

LOBATO, A.K.S.; SANTOS, D.G.C.S.; OLIVEIRA, F.C. et al. Ação do óleo essencial de Piper aduncum L. utilizado como fungicida natural no tratamento de sementes de Vigna unguiculata (L.) Walp. Revista Brasileira de Biociências, v. 5, supl.2, p. 915-917, 2007.
LOPES, K.P.; BRUNO, R.L.A.; BRUNO, G.B. et al. Produtos naturais e fosfeto de alumínio no tratamento de sementes de feijão-macassar (Vigna unguiculata (L.) Walp.) armazenadas. Revista Brasileira de Sementes, v.22, n.2, p.109-117, 2000.

Menten, J.O.M. Patógenos em Sementes, Deteç̧ão, Danos e Controle Químico. São Paulo: Ciba Agro, 1995.

MESQUITA, P.R.R.; NUNES, E.C.; SANTOS, F.N. et al. Discrimination of Eugenia uniflora L. biotypes based on volatile compounds in leaves using HS-SPME/GC-MS and chemometric analysis. Microchemical Journal, v.130, p.79-87, 2017.

PIVETA, G.; MENEZES, V.O.; PEDROSO, D.C. et al. Superação de dormência na qualidade de sementes e mudas: influência na produção de Senna multijuga (L. C. Rich.) Acta

Amazônica, v.40, n.2, p.281-288, 2010.

RANI, P.R.; CHELLADURAI, V.; JAYAS, D.S. et al. Storage studies on pinto beans under different moisture contents and temperature regimes.

Journal of Stored Products Research, v.52, p.78-85, 2013.

REY, M.S.; LIMA, N.B.; SANTOS, J. et al. Transmissão semente-plântula de Colletotrichum lindemuthinum em feijão (Phaseolus vulgaris). Arquivos do Instituto Biológico, v.76, n.3, p.465-470, 2009.

SINGH, D.; KOHLI, R.K.; SAXENA, D.B. Effect of eucalyptus oil on germination and growth of Phaseolus aureus Roxb. Plant and Soil, v.137, p.223-227, 1991. DOI: 10.1007/BF00011200.

SOUZA, A.L. Sanidade de Sementes de feijão em função da palhada antecessora em área de semeadura direta. TESE (doutorado). Universidade Estadual Júlio de Mesquita Filho - UNESP, 2016. 59p.

STONE, L.F.; FERREIRA, E.P.B.; DIDONET, A.D. et al. Correlação entre a produtividade do feijoeiro no sistema de produção orgânica e atributos do solo. Revista Brasileira de Engenharia Agrícola e Ambiental, v.17, n.1, p.9-25, 2013. 
TOLEDO, M.Z.; FONSECA, N.R.; CÉSAR, M.L. et al. Qualidade fisiológica e armazenamento de sementes de feijão em função da aplicação tardia de nitrogênio em cobertura. Pesquisa

Agropecuária Tropical, v.39, n.2, p.124-133, 2009.

VICTORIA, F.N.; LENARDÃO, E.J.; SAVEGNAGO, L. et al. Essential oil of the leaves of Eugenia uniflora L.: antioxidante and antimicrobial properties. Food and Chemical Toxicology, v.50, p.2668-2674, 2012.
WENDLAND, A.; MOREIRA, A.S.; BIANCHINI, A. et al. Doenças do Feijoeiro. In: AMORIM, L.; REZENDE, J.A.M.; BERGAMIN FILHO, A. et al. Manual de Fitopatologia: Doenças das plantas cultivadas. 5 ed. Ouro Fino: Agronômica Ceres, Cap.39, p.383-396, 2016.

ZUCHI， J.; FRANÇA-NETO, J.B.; SEDIYAMA, C.S. et al. Physiological quality of dynamically cooled and stored soybean seeds. Journal of Seed Science, v.35, n.3, p.353-360, 2013.

Recebido para publicação em 17/6/2017 e aprovado em 5/9/2017. 